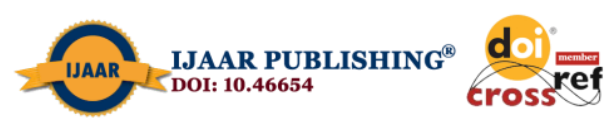

International Journal of Advanced Academic Research | ISSN: 2488-9849

Vol. 7, Issue 3 (March, 2021) | www.ijaar.org

Journal DOI: www.doi.org/10.46654/ij.24889849

Article DOI: www.doi.org/10.46654/ij.24889849.e7303

\title{
Effects of Polycyclic Aromatic Hydrocarbons (PAHs) on the Environment: A Systematic Review
}

\author{
Anyahara, Jessica Nene \\ Department of Environmental Management, Federal University of Technology, Owerri, Imo \\ State, Nigeria
}

\begin{abstract}
This systematic review discussed the effects of Polycyclic Aromatic Hydrocarbons (PAHs) on the Environment. Indiscriminate burning of Organic materials, petroleum product and other industrial processes as well as various runoffs from roads and railways has contributed significantly to environmental pollution by PAHs, which endangers the lives of organisms living in the environment. These PAHs bind strongly to sediments and serve as a long-term source of contaminants in water bodies and biota long after the original source has been removed. Sources of PAHs can be petrogenic, from petroleum-related activities or pyrogenic (pyrolytic), from the incomplete combustion of diesel fuel and engine oil. Also, wood, coal, biomass of forest, grass fires, waste incinerators, and fossil fuels that are used in industrial operations and power plants are all sources of PAHs. PAHs enter the environment through atmospheric deposition and direct releases of substances through petroleum spills and use, municipal wastewater treatment plants, industrial discharges, storm water runoff, landfill leachate, and surface runoff. Generally, the adverse effect of PAHs on the environment is determined by monitoring the sediment/soil, water, and air. Although there is no known short-term health effect of PAHs, but there are several health challenges associated with the long-term accumulation of PAHs in the food chain. Long term exposure to even the simplest PAHs like Naphthalene can lead to kidney and liver damage as well as cataract. It causes redness and inflammation of skin when in contact and red blood cell damage when inhaled, Dibenzopyrene is highly carcinogenic.
\end{abstract}




\section{INTRODUCTION}

Polycyclic aromatic hydrocarbons (PAHs) are a typical group of chemicals containing two or more aromatic rings and are prevalent in the environment. Because of their persistence, carcinogenicity, toxicity and mutagenicity (Marin-Morales et al., 2009), PAHs are of particular concern and 16 priority PAHs are regulated by the United States Environmental Protection Agency (USEPA). For decades, the distribution and sources of PAHs have been the focus of numerous investigations (Soclo et al., 2000; Doong and Lin, 2004; Chen and Chen, 2011; Bar-akat et al., 2011). PAHs can be derived from natural sources, but anthropogenic activity is generally considered to be the major source of PAHs (Baumard et al., 1998). Pyrogenic and petrogenic sources are two major origins of anthropogenic PAHs in the environment. Pyrogenic PAHs are formed as trace contaminants by the incomplete combustion of organic matter, such as wood, fossil fuels, asphalt and industrial waste. Petrogenic PAHs are usually contained in crude and refined petroleum (Liu et al., 2009).

Once produced, PAHs can be transported to the marine environment through wastewater discharge, surface runoff, atmospheric deposition and other means, such as oil leaks (Heemken et al., 2000). In the marine environment, PAHs adhere tightly to sediments because of their high hydrophobicity and weak degradation (Warren et al., 2003). When the environmental conditions change, the adsorbed PAHs can be resuspended into the water via chemical and biological processes, which thus cause secondary pollution to the surroundings (Wang et al., 2010; Lu et al., 2012). Therefore, sediments act both as an important reservoir and as a secondary source for PAH contamination, and the investigation of sedimentary PAHs is needed to provide estimates of PAH inputs into marine areas.

The environmentally significant PAHs are those molecules that contain 2 to 7 benzene rings. PAHs are divided into two groups based on their physical, chemical, and biological characteristics (Martinez et al., 2004). The lower-molecular-weight PAHs, for example, the 2 to 3 rings of PAHs such as naphthalenes, fluorenes, phenanthrenes, and anthracenes, have significant acute toxicity to aquatic organisms. The high-molecular-weight (HMW) PAHs, containing 4 to 7 rings, from chrysenes to coronenes, do not cause acute toxicity but are known to be carcinogenic. Sixteen PAH compounds have been identified as priority pollutants due to their toxic, mutagenic, and carcinogenic characteristics (Tam et al., 2001).

Due to their low water solubility and high lipophilic nature, PAHs are easily and rapidly absorbed by organisms and can be accumulated in aquatic organism or adsorbed onto the surface of suspended matter, get deposited on the sea floor and be passed onto the marine food chain. Although hundreds of PAHs exist, some of the environmentally essential PAHs are: naphthalene, acenaphthylene, acenaphthene, flourene, phenanthrene, anthracene, flouranthene, pyrene, benz[a]anthracene, chrysene, benzo[ $b]$ fluoranthene, benzo[k]flouranthene, benzo $[a]$ pyrene, benzo[ghi]perylene, dibenz $[a, h]$ anthracene, and indeno[1,2,3-cd]pyrene. Four isotopically labeled polynuclear aromatic hydrocarbons (acanaphthene- $d 10$, phenanthrene- $d 10$, chrysene- $d 12$ and perylene- $d 12$ )

Sources of PAHs can be either petrogenic, from petroleum-related activities or pyrogenic (pyrolytic), from the incomplete combustion of diesel fuel and engine oil (Szewczynska et al., 2013). Also, wood, coal, biomass of forest, grass fires, waste incinerators, and fossil fuels 
that are used in industrial operations and power plants are all sources of PAHs (Ashraf et al., 2013). PAHs can be found in tire wear debris, asphalt particles (Srogi K., 2007) and stationary combustion sources (Santasiero et al., 2005). Sources of PAHs in urban atmosphere include automobiles, re-suspended soils, refineries and power plants (Omar et al., 2002; Yang et al., 2002; Dyke et al., 2003). PAHs are also widely used in commercial products, such as intermediaries in pharmaceuticals, agricultural products, photographic products, thermosetting plastics, and lubricating materials. PAHs also occur in large amounts in sedimentary rocks and petroleum (Lichtfouse et al., 1997, 1999; Henner et al., 1999). Additional contributions to ambient air levels arise from tobacco smoking (Sakai et al., 2002), while the use of heating sources can increase PAH concentrations in indoor air. Natural sources such as forest fires and volcanic eruptions are less important. The fate of PAHs is determined by their physicochemical properties, especially nonpolarity and hydrophobicity which is responsible for their persistence in the environment. PAHs from fuel oils tend to be quickly adsorbed onto particles and to accumulate in sediments (Tolosa et al., 2004).

PAHs enter the environment through atmospheric deposition and direct releases of substances through petroleum spills and use, municipal wastewater treatment plants, industrial discharges, storm water runoff, landfill leachate, and surface runoff. PAHs attach readily to sediment particles, leading to high concentrations in bottom sediments of water bodies. A literature review on tire wear particles in the environment indicates that the high aromatic (HA) oils generally used in tires contain PAHs, (Urban Waterways, 2001).

Bioavailability of PAHs and heavy metals occurring in soil is the basic source of its accumulation in crops, herbs and soil micro organisms. The impact of soil pollution on food chain presents a challenge for many investigations.

Generally, the adverse impact of PAHs to the environment is determined by monitoring the sediment/soil, water, and air. Different upland activities in the recent time has contributed significantly to environmental degradation partly due to poor waste management practices and weak enforcement in ensuring that auto mechanic operators are located in designated sites.

Concentrations of PAHs in river and soil vary according to a variety of factors including proximity to municipal and industrial discharge points, upland activities, wind direction and distance from major urban roadways.

Indiscriminate burning of Organic materials, petroleum product and other industrial processes such as, markets, petrol stations, auto-mechanic villages, abattoirs as well as various runoffs from roads and railways has contributed significantly to environmental contamination by PAHs, which endangers the lives of organisms. These PAHs bind strongly to sediments and serve as a long-term source of contaminants in water bodies and biota long after the original source has been removed. There are several Health problems associated with bioaccumulation of PAHs and heavy metals in the food chain. Long term exposure to even the simplest PAHs like Naphthalene can lead to kidney and liver damage as well as cataract. It causes redness and inflammation of skin when in contact and red blood cell damage when inhaled, Dibenzopyrene is highly carcinogenic. 


\section{CONTAMINATIONS IN THE ENVIRONMENTAL COMPONENTS BY POLYCYCLIC AROMATIC HYDROCARBONS (PAHS)}

\subsection{Air Contamination}

According to INCHEM (2011), PAHs are often released into the air, or they evaporate into the air when they are released to soil or water. PAHs often adsorb to dust particles in atmosphere, where they undergo photo oxidation in the presence of sunlight, especially when they are adsorbed to particles. This oxidation process can break down the chemical over a period of days to week. PAHs, as semi-volatile organic compounds, exist in both the gaseous and the particulate phase in air, and are subject to both vapor and particle washout from the atmosphere during precipitation.

\subsection{Water Contamination}

PAHs is an environmental contaminant of great concern, it enters surface waters mainly via atmospheric fallout, urban run-off, municipal effluents, industrial effluents and oil spillage or leakage. Atmospheric fallout includes wet and dry deposition of particles and vapors. A significant amount of PAHs carried to surface waters by sewers derives from urban run-off. Urban run-off consists of the storm water from impervious areas, such as roads, motorways, paved parking lots, abattoirs, mechanic workshops, waste dumpsites and so on.

Since PAHs are generally insoluble in water, they are generally found adsorbed on particulate and precipitated in the bottom of lakes and rivers, or solubilized in any oily matter which may contaminate water. Atmospheric deposition is considered to be an important input of PAHs to surface waters. It has been estimated that $10-80 \%$ of PAH inputs to the world's oceans is from atmospheric sources. As a consequence, urban run-off contains PAHs deposited on surfaces, as well as mobile-related PAHs from gasoline and oil drips or spills, exhaust products, tyre particles, and bitumen from road surfaces. Higher concentrations of PAHs in urban runoff were found during autumn and winter, due to the high incidence of vehicles in the streets, coupled with the use of heating systems (Manoli and Samara, 1999).

\subsection{Soil Contamination}

Another environmental component that faces huge contamination from PAHs is the soil. According to Peter (2003), PAHs in soil are unlikely to exert toxic effect on terrestrial invertebrates, except when soil is contaminated. Although, plant can absorb PAHs from soils through their roots and translocate them to other plant parts. Uptake rates are generally governed by concentration, water solubility and their physicochemical state as well as soil type. Certain plants contain substances that can protect against effect, whereas other can synthesize PAHs that act as growth hormones (ATSDR 2010).

Accumulation of PAHs in soils may lead to further potential contamination of vegetables and food chains (Kipopoulou et al., 1999; Mueller and Shann, 2006), and then cause direct or indirect exposure to human. Moreover, leaching, evaporation and migration are possible PAHs sources of atmospheric or groundwater contamination. Therefore, knowledge of soil contamination with PAHs is needed to avoid any food production risk and to restrict the deleterious effect of these contaminants.

\subsection{SOURCES OF CONTAMINATIONS}

The following list will serve to illustrate typical contaminations sources, although it will be impossible to list all the potential sources of chemical contaminants.

$>$ Petrol stations. 
$>$ Mechanic workshops.

$>$ Chemical manufacturing plants.

$>$ Abattoirs

$>$ Incinerators and incineration activities.

$>$ Chemical waste storage facilities.

$>$ Oil refineries.

$>$ Automobile engine (Osu et al., 1999).

The major environmental concerns in urban and industrial areas are polycyclic aromatic hydrocarbons. They have a relatively low solubility in water, but are highly lipophilic (WHO, n.d.). When dissolved in water or absorbed on particulate matter, PAHs can undergo photodecomposition when exposed to ultraviolet light from solar radiation. In the atmosphere, PAHs can react with pollutants such as ozone, nitrogen oxides and sulphurdioxides, yield diones, nitro - and dinitro- PAHs and sulphonic acids, respectively. They may also be degraded by some microorganisms in soil (ATSDR, 1994). PAHs pollutants have high molecular mass, PAHs of 4 and more condensed aromatic rings are considered to be more dangerous than 2 and 3 rings PAHs in view of their potentials (Kawamura et al., 1994).

Table 1: Industrial activities associated with the production, processing, use, and disposal of PAH- contaminating materials (Duan et al., 2014)

\begin{tabular}{|c|c|c|}
\hline $\mathbf{S} / \mathbf{N}$ & Industrial Activities & Predominant PAHs \\
\hline 1. & Gasification/liquefaction of fossil fuels & $\begin{array}{l}\text { Gasification/liquefaction of fossil fuels } \\
\text { Fluoranthene, Pyrene and Chrysene and } \\
\text { Benzo(a)pyrene }\end{array}$ \\
\hline 2. & Coke production & $\begin{array}{l}\text { Anthracene, Phenanthrene and } \\
\text { Benzo(a)pyrene }\end{array}$ \\
\hline 3. & Catalytic cracking & $\begin{array}{l}\text { Fluoranthene, pyrene, benzo(b)fluoranthene, } \\
\text { benzo(k)fluoranthene and thiophene } \\
\text { compounds }\end{array}$ \\
\hline 4. & Carbon-black production and use & Fluoranthene and Benzo(a)pyrene \\
\hline 5. & Asphalt production and use & $\begin{array}{l}\text { Phenanthrene, Fluoranthene, Pyrene and } \\
\text { Chrysene and Benzo(a)pyrene }\end{array}$ \\
\hline 6. & $\begin{array}{l}\text { Coal-tar/coal-tar-pitch production and } \\
\text { use }\end{array}$ & Phenanthrene, fluoranthene and pyrene \\
\hline 7. & $\begin{array}{l}\text { Refining/distillation of crude oil and } \\
\text { crude oilderived products }\end{array}$ & Pyrene and benzo(a)pyrene \\
\hline 8. & $\begin{array}{l}\text { Wood-preservative and wood } \\
\text { combustion }\end{array}$ & Fluoranthene and Benzo(a)pyrene \\
\hline 9. & $\begin{array}{l}\text { Fuel/oil storage, transportation, } \\
\text { processing, use and disposal }\end{array}$ & $\begin{array}{l}\text { Fluoranthene, pyrene, benzo(b)fluoranthene, } \\
\text { benzo(k)fluoranthene and thiophene } \\
\text { compounds }\end{array}$ \\
\hline 10. & Open burning (tyres/refuse/coal etc.) & Phenanthrene and Anthracene \\
\hline 11. & Incineration & Pyrene,Phenanthrene and fluoranthene \\
\hline
\end{tabular}


The movement of PAHs in the environment depends on properties such as how easily they dissolve in water and how easily they evaporate in the air (Jaarsveld et al., 1997). As persistent organic pollutants (POPs), some of them are susceptible to dispersion on a global scale because in addition to having environmental persistence, they move between the atmosphere and earth's surface in repeated, temperature-driven cycles of deposition and volatilization (Jaarsveld et al., 1997). POPs are truly multimedia contaminants which occur in all parts of the environment: atmosphere, inland and sea water, sediments, soil and vegetation (Paterson and Mackay, 1989; Jaarsveld et al., 1997). They are mainly of anthropogenic origin and have only a few significant natural sources (Fetzer, 2000). The most commonly encountered POPs are Organochlorine pesticides, such as DDT, industrial chemicals like polychrorinated biphenyls (PCB) and dioxins. PAHs (which are known for their strong mutagenic, carcinogenic and toxic properties) are composed of carbon and hydrogen atoms arranged in the form of fused benzene rings. There are thousands of PAHs compounds in the environment but in practice PAHs analysis is restricted to the determination of 6 to 16 PAHs as priority pollutants, while some of these, e.g. benzo (a) pyrene, chrysene, benzo (a) anthracene are considered to be potential human carcinogens. PAHs are the most toxic among the hydrocarbon families (Catoggio, 1991). Individual PAHs differ substantially in their physical and chemical properties (Malisezewska-Kordybach, 1998). The widespread occurrence of PAHs is largely due to their formation and release in all processes of incomplete combustion of organic materials. The last century of industrial development caused a significant increase of PAHs concentrations in the natural environment (Wild and Jones, 1993).

The simplest PAHs are phenanthrene and anthracene. PAHs may contain four, five, six, or seven - membered rings, but those with five or six are most common. PAHs that comprised only of six-membered rings are called alternant PAHs. Certain alternate PAHs are called benzenoid PAHs. PAHs containing up to six fused aromatic rings are often known as small PAHs and those containing more than six aromatic rings are called large PAHs (Pure Applied Chemistry, 2009).

PAHs in the environment are found primarily in water, soil, sediment, and oily substances, as opposed to being in water or air. However, they are also a component of concern in particulate matter suspended in the air. The National Institute for Occupational Safety and Health (NIOSH) has determined that PAHs are a "potential occupational carcinogen". Although the health effects of individual PAHs are not exactly alike, the following 17 PAHs are profiled as a group of those detrimental to health: acenaphthene, acenaphthylene, anthracene, benz[a]anthracene, $\mathrm{BaP}$ benzo[e]pyrene, benzo[b]fluoranthene, benzo[g,h,i]perylene, benzo[j]fluoranthene, benzo[k]fluoranthene, chrysene, dibenz[a,h]anthracene, fluoranthene, fluorene, indeno[1,2,3-c,d]pyrene, phenanthrene, and pyre. 


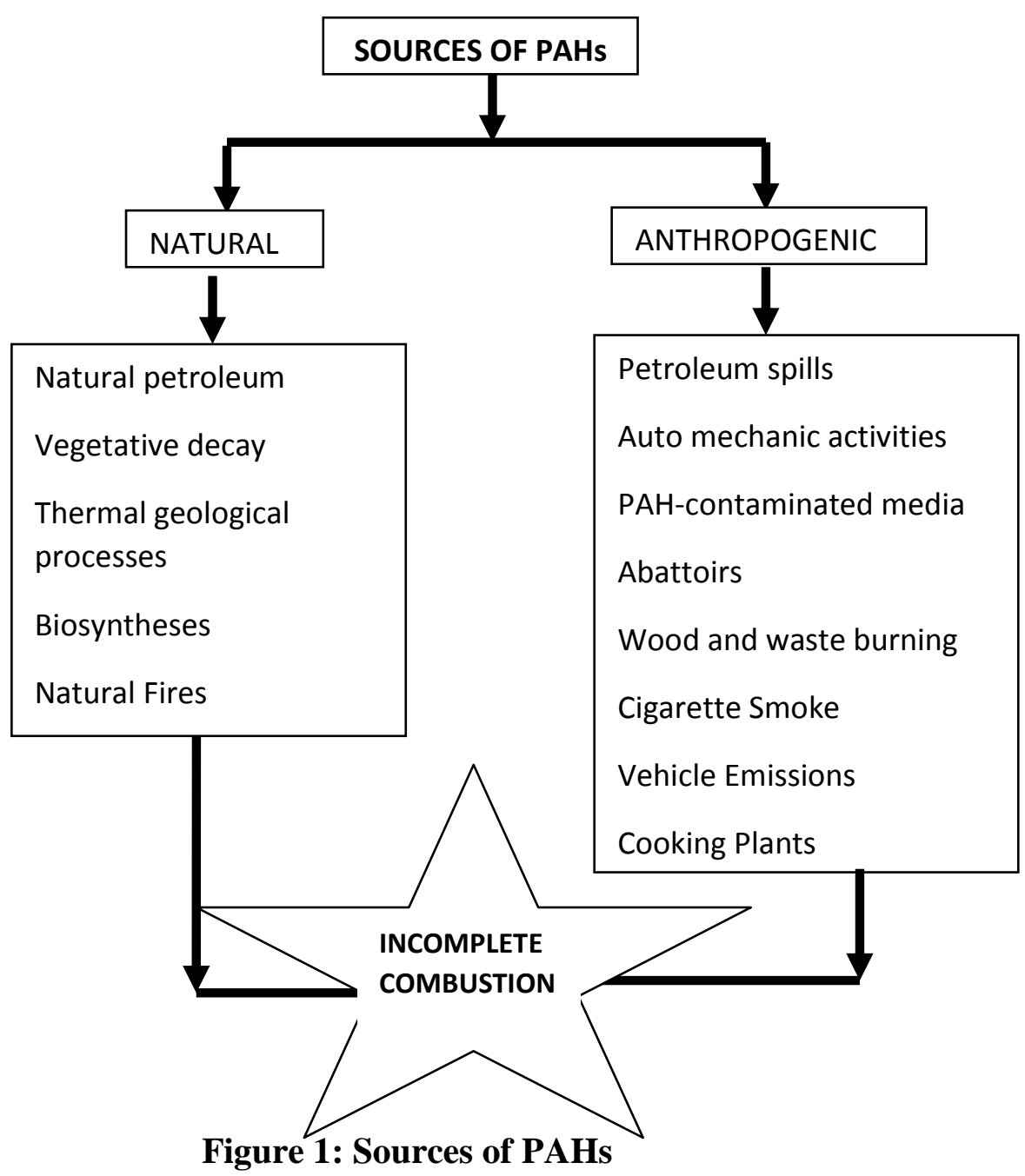

\section{EFFECTS OF PAHs}

\subsection{Environmental Effects}

PAHs are usually released into the air, or they evaporate into the air when they are released to soil or water (INCHEM, 2011). PAHs often adsorb to dust particles in the atmosphere, where they undergo photo oxidation in the presence of sunlight, especially when they are adsorbed to particles. This oxidation process can break down the chemical over a period of days to week. Since PAHs are generally insoluble in water, they are generally found adsorbed on particulate and precipitated in the bottom of lakes and rivers, or solubilized in any oily matter which may contaminate water. Sediments and soil, mixed microbial population in sediment may degrade some PAHs over a period of weeks to months (ATSDR, 2010).

The toxicity of PAHs is affected by metabolism and photo-oxidation, and they are generally more toxic in the presence of ultraviolet light. PAHs have moderate to high acute toxicity to aquatic life and birds. 
PAHs in soil are unlikely to exert toxic effect on terrestrial invertebrates, except when soil is contaminated (Peter, 2003).

Adverse effects on these organisms include tumors, adverse effects on reproductive organs, development and immunity, mammals can absorb PAHs by various routes e.g. inhalation, dermal contact and ingestion (ATSDR, 1994). Plant can absorb PAHs from soils through their roots and transfer them to other plant parts. Uptake rates are generally governed by concentration, water solubility and their physicochemical state as well as soil type. PAH induced phytotoxic effect are rare. Certain plants contain substances that can protect against adverse effect, whereas others can synthesize PAH that act as growth hormones (ATSDR, 2010).

\subsection{Health Effects}

\section{Acute or Short-Term Health Effects.}

It is not clear that PAHs cause short-term health effects. Long-term health effects of exposure to PAHs may include cataracts, kidney and liver damage, and jaundice. Repeated skin contact to naphthalene can result in redness and inflammation of the skin. Breathing or swallowing large amounts of naphthalene can cause the breakdown of red blood cells. Long-term exposure to low levels of some PAHs has caused cancer in laboratory animals. Benzo(a)pyrene is known to cause cancer in experiment animals. Studies of workers exposed to mixtures of PAHs and other compounds have noted an increased risk of skin, lung, bladder, and gastrointestinal cancers. A number of individual PAHs are classified by the International Agency of Research on Cancer as carcinogenic to animals and probably carcinogenic to humans. Exposure is through the anthropogenic sources mentioned above exposure is greatest for workers in industrial and chemical processes. General exposure is through cigarette smoke, car exhaust gases and food. It is difficult to quantify exposure, due to the large number of PAHs. Benzo[a]pyrene $\mathrm{B}[\mathrm{a}] \mathrm{P}$ has been chosen as a marker for the total mixture of PAHs in the United Kingdom. The level recommended by the Expert Panel on Air Quality Standards (United Kingdom) for B[a]P as a marker for total PAHs is $0.25 \mathrm{ng} / \mathrm{m} 3$ measured as an annual average. The effects on human health will depend mainly on the length and extent of exposure, the amount or concentration of PAHs the person is exposed to, and of course the innate toxicity of the PAHs, and whether exposure occurs via inhalation ingestion or skin contact. (Srogi, 2007). A variety of other factors can also affect health impacts, including subjective facts such as pre-existing health status and age (Collins et al., 1998).

The ability of PAHs to induce short-term health effects in human is not clear. Intake of PAHs from contaminated soil occurs via ingestion, inhalation or dermal (skin) exposure to contaminated soil/dust and from inhalation of PAH vapours. Tilling the dry soil can result in ingestion of small but measurable amount of soil.

Occupational exposure to high level of pollutant mixture containing PAH has resulted in symptoms such as eye irritation, nausea, vomiting and diarrhea (Collins et al., 1998).

However, it is not known which components of the mixture where responsible for the effect and other compounds commonly found with PAHs may be the cause of these symptoms. 


\section{Chronic or Long-term Health Effects}

Health effect from chronic or long-term exposure to PAHs may include decrease in immune function, cataract, kidney and liver damage (e.g. jaundice), and breathing problems, asthma like symptoms and lung function abnormalities and repeated contact with skin may induce redness and skin inflammation (Miller et al., 2001). Naphthalene, a specific PAH, can cause the breakdown of red blood cell if inhaled or ingested in large amounts (Collins et al., 1998). When exposed to PAHs, the harmful effect that may occur will largely depend on the nature of exposure (BBC News, 2001).

Some chronic effects of PAHs include Carcinogenicity, Genotoxicity, and Teratogenicity.

\section{Carcinogenicity}

Although unmetabolized PAHs can have toxic effect, a major concern is the ability of the reactive metabolities, such as epoxides and dihydrodiols, of some PAHs to bind to cellular proteins and DNA. The resulting biochemical disruption and cell damage leads to Mutations, developmental malformation, tumors, and cancer.

Evidence indicates that mixtures of PAHs are carcinogenic to humans (Grimmer, et al., 1988). The evidence came primarily from occupational studies of workers exposed to mixtures containing PAHs and these long-term studies have shown an increase in risk of predominantly skin and lung, but as well as bladder and gastrointestinal cancers. However, it is not clear from these studies whether exposure to PAHs was the main cause as workers were simultaneously exposed to other cancer - causing agent (e.g. aromatic amines) (Grimmer, et al., 1988).

Animals exposed to level of some PAH over long period in laboratory studies have developed lung cancer from inhalation, stomach cancer from ingesting PAHs in food and skin contact. Benzo (a) pyrene is the most common PAH to cause cancer in animal and this compound is notable for being the first chemical carcinogen to be discovered. Based on the available evidence both the International Agency for Research on cancer (IARC, 1987) classified a number of PAHs as carcinogenic to animal and some PAH - rich mixture as carcinogenic to human (ATSDR, 1994). The EPA has classified seven PAH compound as probable human carcinogens: benz(a)anthracene, benzo(a)pyrene, benzo(b)fluoranthene, benzo(k)fluoranthene, chrysene, dibenz(ah)anthracene, and indeno(1,2,3-cd)pyrene.

\section{Teratogenicity}

Embroyotoxic effect of PAHs have been described in experimental animal exposed to PAH such as benzo (a) anthracene, benzo (a) pyrene and naphthalene. Laboratory studies conducted on mice have demonstrated that ingestion of high level of benzo (a) pyrene during pregnancy resulted in birth defects and decreased body weight in the offspring. It is not known whether these effects can occur in human. However, the center for Children's Environmental Health reports studies demonstrate that exposure of PAH pollution during pregnancy is related to adverse birth outcomes including how birth weight, premature delivery and heart alformations. High prenatal exposure to PAHs is also associated with lower 1Q at age three, increased behavioural problems at ages of six and eight. Childhood asthma cord blood of exposed babies shows DNA damage that has been linked to cancer.

\section{Genotoxicity}

Genotoxic effects for some PAH have been demonstrated both in rodents and in visto tests using mammalian (including human) cell lines. Most of the PAHs are not genotoxic by 
themselves and they need to be metabolized to the diol exposed which react with DNA, thus inducing genotoxic damage. Genotoxicity plays important role in the carcinogenity process and maybe in some forms of developmental toxicity as well.

\section{Characteristics of PAHs}

The majority of research on PAHs has been conducted on the small PAHs due to the availability of samples of them, (IARC, 2010). The general characteristics of PAHs are high melting and boiling points (therefore making them solid), low vapor pressure, and very low aqueous solubility, the latter two tending to decrease with increasing molecular weight, whereas their resistance to oxidation and reduction increases with higher molecular weight. PAHs are highly lipophilic and therefore very soluble in organic solvents. PAHs also manifest various properties such as light sensitivity, heat resistance, conductivity and resistance to corrosion, as well as have a variety of physiological actions. PAHs possess very characteristic Ultra violet (UV) absorbance spectra. Each ring structure has a unique UV spectrum, and thus each isomer has a different UV absorbance spectrum. This characteristic is especially useful in the identification of PAHs. Most PAHs are also fluorescent, emitting characteristic wavelengths of light when they are excited (when the molecules absorb light). Aqueous solubility decreases with each additional ring. The simplest PAHs, as defined by the International Union of Pure and Applied Chemistry (IUPAC), are phenanthrene and anthracene, both of which contain three fused aromatic rings. Smaller cyclic molecules, such as benzene, are not PAHs. Naphthalene, which consists of two coplanar six-membered rings sharing an edge, is another aromatic hydrocarbon.

\section{Classification and Properties of PAHs}

Polycyclic Aromatic Hydrocarbons (PAHs) are a sizable group of compounds consisting only of carbon and hydrogen (therefore being organic), with two or more condensed aromatic rings. They play an important role in the assessment and control of air quality as they include a large number of chemicals that can be considered hazardous for the environment and for human health. For this reason, they are strictly regulated by law in most industrialized countries. PAHs are generally considered to be Semi-Volatile Organic Compounds (SVOCs); their volatility is strongly related to the number of aromatic rings as well as the molecular structure. Naphthalene (two benzenoid rings), the simplest PAH, has the lowest boiling point $\left(218^{\circ} \mathrm{C}\right)$ and is relatively volatile, while PAHs with more than 5 rings are considered scarcely volatile, as boiling points generally increase with the number of rings. PAHs have low vapour pressures and are found at ambient temperature in air both as vapours and associated with particles. They are relatively insoluble in water, but dissolve easily in fats and oils. In combustion systems, they are typically present as gases but can be emitted from the stack both as vapour and particulate matter. Some of the PAHs more frequently tested for in emissions are Benzo[a]pyrene (B[a]P), Acenaphthene, Dibenzo(a,h)anthracenes, Anthracene, Fluoranthene, Fluorene, Naphthalene, Phenanthrene, Chrysene and Pyrene.

\section{Bioavailability of PAHs}

Bioavailability defines the accessible fraction of a contaminant in soil and is more relevant to environmental and health risk assessment than total concentrations. There is increasing evidence that many contaminants persisting in the environment are influenced greatly by soil properties and become progressively less available for uptake by organisms over time, thereby becoming less toxic or susceptible to biodegradation and bioremediation by microorganisms (Naidu et al., 2008). 
The extent to which a soil contaminant is bioavailable to crops and plants depends on a variety of factors including the properties of the contaminant and the soil, as well as the exposure pathway (Bolan et al., 2006). Oral ingestion of contaminated soil is one of the most important exposure pathways of soil-bound contaminants for humans, and accidental ingestion of large amounts of soil by children represents a worst-case scenario for acute exposures (CCME, 2010).

Benzo[a]Pyrene $(\mathrm{B}[\mathrm{a}] \mathrm{P})$ is a well-known carcinogen that is generated from both natural and anthropogenic combustion processes. It is a common environmental contaminant and has been required in the routine analysis of soil when land use is changed. The new National Environmental Protection Measure (NPEM) in Australia were established based on the assumption that bioavailability of $\mathrm{B}[\mathrm{a}] \mathrm{P}$ from both oral and inhalation pathway is $100 \%$ due to the lack of reliable information on its bioavailability in contaminated soils (Duan et al., 2014). 


\section{REFERENCES}

AGENCY FOR TOXIC SUBSTANCE AND DISEASE REGISTRY (ATSDR). (2010). Public Health Statement. August 1995.[Accessed $1^{\text {st }}$ March, 2021]

AGENCY FOR TOXIC SUBSTANCES AND DISEASE REGISTRY (ATSDR). (1994). Toxicological profile for polycyclic aromatic hydrocarbons (PAHs): update. Atlanta, GA, US Department of Health and Human Services, Public Health Services, 1994.

Barakat, A.O., Mostafa, A., Wade, T.L., Sweet, S.T., and ElSayed, N.B. (2011). Distribution and characteristics of PAHs in sediments from the Mediterranean coastal environment of Egypt. Mar. Pollut. Bull. 62, 1969-1978.

Baumard P., Budzinski H., and Garrigues P. (1998). Polycyclic aromatic hydrocarbons in sediments and mussels of the western Mediterranean sea Environ. Toxicol. Chem. 17 765-776

BBC News. Incense Link to Cancer. (http//news-bbc.co.uk/2/hi/health) 2-08-2001

Bolan, N.S., S. Mahimairaja., M. Megharaj., and R. Naidu. (2006): Biotransformation of arsenic in soil and aquatic environments in relation to bioavailability and bioremediation, in Managing Arsenic in the Environment: From Soil to Human Health, R. Naidu, et al., Editors. 2006, CSIRO Publishing. p. 433-454.

Canadian Council of the Ministers of the Environment (CCME). (2010): Canadian environmental quality guidelines-Canadian soil quality guidelines for the protection of environmental and human health, 2010, National Guidelines and Standards Office: Quebec.

Catoggio J.A.(1991). Other organic toxic substances - in Guideline of lake management toxic. Substances management in lakes and reservoirs 4: 113-126.

Chen, C.W., and Chen, C.F. (2011).Distribution, origin, and potential toxicological significance of polycyclic aromatic hydrocarbons (PAHs) in sediments of Kaohsiung Harbor. Taiwan. Mar. Pollut. Bull. 63, 417-423

Collins, J.F., J. P. Brown, G. V. Alexeeff, and A. G. Salmon. (1998): Potency equivalency factors for some polycyclic aromatic hydrocarbons and polycyclic aromatic hydrocarbon derivatives. Regulatory Toxicology and Pharmacology, 28: 45-50.

Doong, R.A., and Lin, Y.T. (2004). Characterization and distribution of polycyclic aromatic hydrocarbon contaminations in surface sediment and water from Gaoping River, Taiwan. Water Res. 38, 1733-1744.

Duan, L., T. Palanisami, Y. Liu, Z. Dong, M. Mallavarapu, T. Kuchel, K.T. Semple, and R. Naidu. (2014): Effects of ageing and soil properties on the oral bioavailability of benzo[a]pyrene using a swine model. Environment International, 2014. 70(0): p. 192202

Dyke P.H, Foan C, Fiedler H.(2003): PCB and PAH releases from power stations and waste incineration processes in the UK. Chemosphere 50:469-480

E. Martinez., M. Gros., S. Lacorte., and D. Barceló. (2004): Simplified procedures for the analysis of polycyclic aromatic hydrocarbons in water, sediments and mussels," Journal of Chromatography A, vol. 1047, no. 2, pp. 181-188, 2004.

Fetzer, John. (2000). The Chemistry and Analysis of the Large Polycyclic Aromatic Hydrocarbons. Polycyclic Aromatic Compounds (New York: Wiley). 27. 143-147.

Grimmer, G., H. Brune, G. Dettbarn, K-W. Naujack, U. Mohr and R. Wenzel-Hartung. (1988). Contribution of polycyclic aromatic compounds to the carcinogenicity of sidestream smoke of cigarettes evaluated by implantation into lungs of rats. Cancer Lett, 43: 173-177 
Heemken, O., Stachel, B., Theobald, N., \& Wenclawiak, B. (2000). Temporal Variability of Organic Micropollutants in Suspended Particulate Matter of the River Elbe at Hamburg and the River Mulde at Dessau, Germany. Archives of environmental contamination and toxicology. 38. 11-31. 10.1007/s002449910003.

Henner P., Schiavon M., Druelle V., and Lichtfouse E. (1999): Phytotoxicity of ancient gaswork soils. Effect of polycyclic aromatic hydro- carbons (PAHs) on plant germination. Org Geochem 30:963-969

IARC (International Agency for Research on Cancer) (1987) IARC monographs on the evaluation of the carcinogenic risk of chemicals to human. Polynuclear aromatic compounds, Part I, Chemical, environmental, and experimental data. World Health Organization, Geneva, Switzerland

IARC (International Agency for Research on Cancer) (2010) Monographs on the evaluation of carcinogenic risk of chemicals to humans, vol 53. International Agency for Research on Cancer, Lyon, France

International programme on chemical safety (INCHEM).(2011): Polycyclic aromatic hydrocarbons,selected nonheterocyclic (EHc 202, 1998) accessed 12.11. 2011.

Jaarsveld, J.A. \& Pul, Addo \& de Leeuw, Frank. (1997). Modeling Transport and Deposition of Persistent Organic Pollutants in the European Region. Atmospheric Environment. 31. 1011-1024. 10.1016/S1352-2310(96)00251-8.

Kawamura K., Suzuki I, Fujii .Y., and Wanatabe O. (1994): Ice core record of Polycyclic aromatic hydrocarbon over past 400 years, Naturwissenschaften 81, 502,

Kipopoulou A.M., Manoli E., and Samara C. (1999): Bioconcentration of polycyclic aromatic hydrocarbons in vegetables grown in an industrial area. Environ Pollut 106:369-380

Lichtfouse E , Apitz S, Nanny M (1999) The biogeochemistry of polycyclic aromatic hydrocarbons. Org Geochem 30:873-969

Lichtfouse E., Budzinski H., Garrigues P., and Eglinton T.I. (1997): Ancient polycyclic aromatic hydrocarbons in modern soils: 13C, 14C and biomarker evidence. Org Geochem 26:353-359.

Liu, Y., Chen, L., Huang, Q.H., Li, W.Y., Tang, Y.J., and Zhao, J.F., (2009). Source apportionment of polycyclic aromatic hydrocarbons (PAHs) in surface sediments of the Huangpu River, Shanghai, China. Sci. Total Environ. 407, 2931-2938.

Lu, M., Zeng, D.C., Liao, Y., and Tong, B. (2012). Distribution and characterization of organochlorine pesticides and polycyclic aromatic hydrocarbons in surface sediment from Poyang Lake, China. Sci. Total Environ. 433, 491-497.

M. Szewczynska, M. Posniak, and E. Dobrzynska. (2013): Study on individual PAHs content in ultrafine particles from solid fractions of diesel and biodiesel exhaust fumes," Journal of Chemistry, vol. 2013, Article ID 528471, 10 pages, 2013.

M. W. Ashraf, S. I. H. Taqvi, A. R. Solangi, and U. A. Qureshi. (2013). Distribution and risk assessment of polycyclic aromatic hydrocarbons in vegetables grown in Pakistan," Journal of Chemistry, vol. 2013, Article ID 873959, 5 pages, 2013.

Maliszewsa - Kordybach B. and Smerczak B.(1998). The content of polycyclic aromatic hydrocarbons (PAH) in agricultural Soils in Lublin district.RocznikiGleboznawcze. T. XL VIII (1- 2).

Manoli E., and Samara C. (1999): Polycyclic aromatic hydrocarbons in natural waters: sources, occurrence and analysis. Tredns Anal Chem 18:717-428

Marin-Morales, Maria \& Leme, Daniela \& Mazzeo, Dânia. (2009). A review of the hazardous effects of polycyclic aromatic hydrocarbons on living organisms. Polycyclic Aromatic Hydrocarbons: Pollution, Health Effects and Chemistry. 1-50. 
Men, B., He, M.C., Tan, L., Lin, C.Y., Quan, X.C., 2009. Distributions of polycyclic aromatic hydrocarbons in the Daliao River Estuary of Liaodong Bay, Bohai Sea (China). Mar. Pollut. Bull. 58, 818-826.

Miller, E.C., and Miller J.A. (2001): Search for Ultimate clinical carcinogens and their reactions with cellular macromolecules. Carcer Res. 47: 2327-2345.

Mueller K.E., and Shann J.R. (2006): PAH dissipation in spiked soil: Impacts of bioavailability, microbial activity, and trees. Chemosphere 64:1006-1014

N. F. Y. Tam, L. Ke, X. H. Wang, and Y. S. Wong. (2001). Contamination of polycyclic aromatic hydrocarbons in surface sediments of mangrove swamps," Environmental Pollution, vol. 114, no. 2, pp. 255-263, 2001.

Naidu, R., K.T. Semple, M. Megharaj, A.L. Juhasz, N.S. Bolan, S. Gupta, B. Clothier, and R. Schulin. (2008): Bioavailability: Definition, assessment and implications for risk assessment. Developments in soil science, 2008. 32: p. 39-51.

Okafor, C. C., and Onwuka, S. U. (2013). Leachate Pollution of Soil of Enugu. IOSR Journal Of Environmental Science, Toxicology And Food Technology (IOSR-JESTFT) eISSN: 2319-2402,p- ISSN: 2319-2399.Volume 5, Issue 5 (Sep. - Oct. 2013), PP 41-47

Omar N.Y.M..J, Abas M.R.B., Ketuly K.A., and Tahir N.M. (2002): Concentra- tions of PAHs in atmospheric particles (PM-10) and roadside soil particles collected in Kuala Lumpur, Malaysia. Atmos Environ 36:247-254

Osu Charles .I. Asuoha, and Adaku N. (1999): Polycyclic aromatic hydrocarbon (PAHs) and Benzene, Toluene,Ethylbenzene, and Xylene (BTEX) contamination of soil in Automobile mechanic workshop in Port-Harcourt Metropolic, River State, Nigeria. Dept of Pure and Ind. Chem, University of Port-Harcourt, P.M.B 5323 Choba, PortHarcourt River State, Nigeria, 242, 243.

Paterson .S, and Mackay D. (1989): A model illustrating the environmental fate exposure and human uptake of the persistent organic chemicals. Ecol. Modeling, 47, 85.

Peter H. Albers (2003):Petroleum and individual Polycyclic aromatic hydrocarbon in D.J. Hoffman, B.A. Rattner,G.A. Buston, J. Cairns editors. Handbook of Ecotoxicology. Lewis Publisher. 342, 359.

Pure Applied Chemistry: A collection of invited, Peerreviewed articles by the winner of 2009 LUPAC Prize for young chemist. 81, 2157-2251. 2009

Sakai R., Siegmann H.C., Sato H., and Voorhees A.S. (2002): Particulate matter and particleattached polycyclic aromatic hydrocarbons in the indoor and outdoor air of Tokyo measured with personal monitors. Environ Res Sec A 89:66-71

Santasiero A, Settimo G, Cappiello G, Viviano G, Dell'Andrea E, Gentilini L (2005) Urban crematoria pollution related to the management of the deceased. Microchem $\mathrm{J}$ 79:307-317

Soclo, H.H., Garrigues, P.H., Ewald, M., 2000. Origin of polycyclic aromatic hydrocarbons (PAHs) in coastal marine sediments: Case studies in Cotonou (Benin) and Aquitaine (France) areas. Mar. Pollut. Bull. 40, 387-396

Srogi, K. (2007). Monitoring of environmental exposure to polycyclic aromatic hydrocarbons: a review. Environmental Chemistry Letters, 5(4), 169-195. https://doi.org/10.1007/s10311-007-0095-0

Tolosa I., de Mora S., Sheikholeslami M.R, Villeneuve J-P., Bartocci J., and Cattini C. (2004): Aliphatic and aromatic hydrocarbons in coastal Caspian Sea sediments. Mar Pollut Bull 48:44-60

Urban Waterways (2001): Polycyclic Aromatic Hydrocarbons (PAHs) in Urban Waters 
Wang, H.S., Zhang, C., Liang, P., Shao, D.D., Kang, Y., Wu, S.C., Wong, C.K., and Wong, M.H., (2010): Characterization of PAHs in surface sediments of aquaculture farms around the Pearl River Delta. Ecotoxicol. Environ. Saf. 73, 900-906.

Warren, N., Allan, I.J., Carter, J.E., House, W.A., and Parker, A. (2003). Pesticides and other micro-organic contaminants in freshwater sedimentary environments-a review. Appl. Geochem. 18, 159-194.

Wild, S.R. and K.C. Jones. (1993): Biological and abiotic losses of polynuclear aromatic hydrocarbons (PAHs) from soils freshly amended with sewage sludge. Environmental Toxicology and Chemistry, 1993. 12(1): p. 5-12.

World Health Organization (WHO): General Description of PAH's. https://www.euro.who.int/_data/assets/pdf_file/0015/123063/AQG2ndEd_5_9PAH.p df

World Health Organization(WHO). International Agency for Research on Cancer-IARC Monographs on the Evaluation of Carcinogenic Risks to Humans, Vol. 92.

Yang H.H., Lai S.O., Hsieh L.T., Hsueh H.J., and Chi T.W.(2002): Profiles of PAH emission from steel and iron industries. Chemosphere 48:1061-1074 